\begin{tabular}{c} 
International Journal of Engineering \& Technology, $7(2)(2018) 584-590$ \\
International Journal of Engineering \& Technology \\
Website: $\begin{array}{c}\text { ww. sciencepubco.com/index.php/IJET } \\
\text { doi: } 10.14419 / \text { ijet. } 7 \text { i } 2.8876 \\
\text { Research paper }\end{array}$ \\
\hline
\end{tabular}

\title{
Flood susceptibility assessment in Kelantan river basin using copula
}

\author{
Mohamed Salem Nashwan ${ }^{1,2}$, Tarmizi Ismail ${ }^{2}$, Kamal Ahmed ${ }^{2,3}$ \\ ${ }^{1}$ Faculty of Engineering and Technology, Arab Academy for Science, Technology and Maritime Transport (AASTMT), Cairo, Egypt \\ ${ }^{2}$ Faculty of Civil Engineering, Universiti Teknologi Malaysia (UTM), 81310 Johor Bahru, Malaysia \\ ${ }^{3}$ Faculty of Water Resources Management, Lasbela University of Agriculture, Water and Marine Sciences, Uthal, Balochistan, Pakistan \\ *Corresponding author E-mail: tarmiziismail@utm.my
}

\begin{abstract}
Bivariate frequency analysis of flood variables of different station locations of Kelantan river basin was conducted using copula for the assessment of the geographical distribution of flood risk. Seven univariate distribution functions of flood variables were fitted with flood variables such as peak flow, flood volume, and flood duration to find the best-fitted distributions. The joint dependent structures of flood variables were modeled using Gumbel copula. The results of the study revealed that different variables fit with different distributions. The correlation analysis among variables showed a strong association. Joint distribution functions of peak-flow and volume, peak-flow and duration, and volume and duration revealed that the joint return periods were much higher than univariate return periods of same flood variables. The flood risk analysis based on joint return period of flood variables revealed the highest risk of devastating flood in the downstream. The locations identified as highly susceptible to flood risk by joint distributing of flood variables had experienced most severe floods in recent history, which indicates the effectiveness of the method for the analysis of flood risk. It is expected that this procedure can be helpful for better assessment of flood impacts.
\end{abstract}

Keywords: Flood Variables; Distribution Fitting; Bivariate Frequency Analysis; Flood Susceptibility; Malaysia.

\section{Introduction}

Reliable assessment of flood frequency and magnitude is essential for effective mitigation planning and designing hydraulic structures [1]. Univariate analysis based on flood peak is generally used for predicting flood occurrence [2]. However, devastating flood does not always depend on peak flow. Destructive floods occur when high flood peak sustain for a longer period or huge volume of flood water inundates an area for a longer time. The duration of the flood is often very important, particularly for structural designing. Flood volume is also required for designing flood protection measures. Therefore, flood hazard can be considered as a multivariate phenomenon depends on different variables such as flood peak flow, flood duration and flood volume [3], [4].

Several studies have been conducted to analyze the flood variables using the multivariate method in order to evaluate flood characteristics [5]. Most of the studies pointed that marginal distribution that best describes the flood parameters are often not from the same probability distribution function [6], [7] and therefore, make the bivariate analysis complicated. To overcome this problem the concept of copula was introduced into flood frequency analysis [8], [9]. Copula allows users to model the correlations among flood variables without considering the type of marginal distributions of flood variables [7], [10]. The evolution of the joint distribution of flood frequency analyses using copula initiated number of studies on the joint distribution of flood variables across the world. Chen, et al. [10] used copula function for multivariate analysis of flood coincidence analysis. Chowdhary, et al. [8] compared different copulas for identification of best-fitted copula for bivariate frequency analysis of flood peak and flood volume. Kao and Chang [9] employed copula for flood frequency analysis in the ungauged river basin of Nashville, USA. Li, et al. [11] adopted copula for bivariate flood frequency analysis using historical information. Reddy and Ganguli [12] used Archimedean copulas for bivariate flood frequency analysis of flood upper Godavari River. Salvadori and De Michele [7] adopted multivariate extreme value methods for analysis for flood. Xie and Wang [13] used joint probability methods for precipitation and flood frequencies analysis. All the above studies indicated copula as a better option for joint parametric distribution. However, application of joint analysis of flood variables is still very limited for flood analysis in Malaysia.

Increasing risk of flood in recent years has posed a major challenge in the Malaysian development [14], [15]. A number of recent studies revealed increasing frequency and severity of rainfall extremes in peninsular Malaysia [16], [17]. It can be anticipated that changes in rainfall pattern have not only changed the return period of flood peak, but also the flood duration and volume. The structural designing in Malaysia is historically based on the analysis of extreme values alone. However, consideration of other flood characteristics in defining flood risk is very important from adaptation and mitigation point of view. Therefore, the objectives of this study are (a) to determine the flood variables namely, annual peak, corresponding duration and volume from historical river discharge data, (b) to estimate the univariate distribution of flood variables, and (c) to perform copula analysis to the modeled joint distribution of flood. 


\section{Study area and datasets}

The Kelantan River (Lat: $4^{\circ} 40^{\prime}-6^{\circ} 12^{\prime} \mathrm{N}$; Lon: $101^{\circ} 20^{\prime}$ and $102^{\circ}$ $20^{\prime} \mathrm{E}$ ) is located in the State of Kelantan in the north east of Peninsular Malaysia (Fig. 1). It is $248 \mathrm{~km}$ long and drains a catchment area of $13,100 \mathrm{~km}^{2}$ [18]. About $95 \%$ of its basin is steep mountains terrain rising to a height of $2,135 \mathrm{~m}$ [18]. The climate of Kelantan River basin is dominated by two monsoons like other parts of the Malaysia, northeast monsoon (Nov-Mar) and southwest monsoon (May-Sep) [19], [20]. The Kelantan River basin is influenced strongly by the northeast monsoon when most of the average annual rainfall $(2,500 \mathrm{~mm})$ occurs [21]. The mean annual flow of the main river is $557.5 \mathrm{~m}^{3} / \mathrm{s}$. Kelantan river has a long history of severe floods [21-24]. More than $90 \%$ of houses in flood affected area were destroyed in 2014 flood [25]. Recently, in 2017 , the floods affected more than 14,000 people who have been evacuated [26]. Due to its high proneness of extreme floods and high financial damage [23], Kelantan river basin was chosen as a case study.

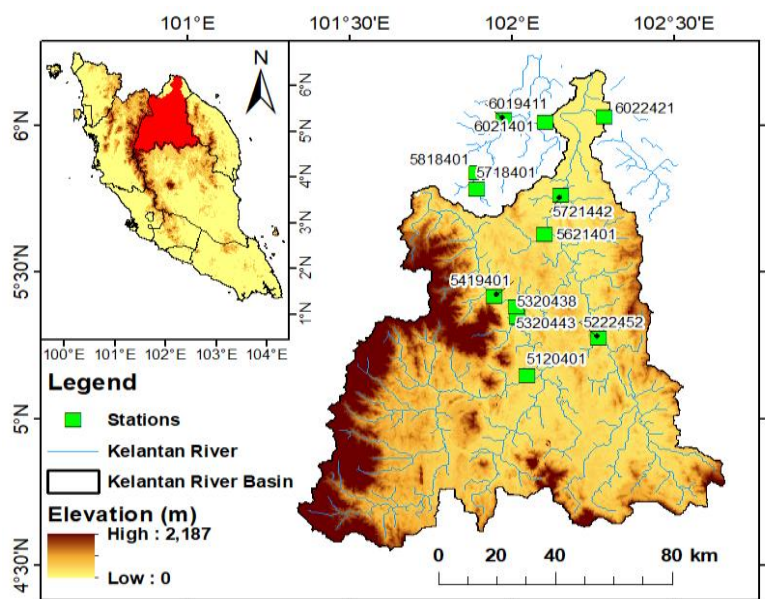

Fig. 1: River Discharge Monitoring Stations in Kelantan in the Map of Peninsular Malaysia.

Forty-three years (1972-2014) hourly river discharge data records from twelve stations distributed over the catchment were used for the study (Fig. 1) and were collected from the Department of Irrigation and Drainage (DID), Malaysia. The years having complete streamflow record were used for analysis. Three out of twelve stations are located outside the Kelantan River basin. Floods in Kelantan River basin is often triggered by the overflow of flood water from nearby catchments. Therefore, available data from those three locations outside the basin which have a very close proximity and influence on the flood of the basin were included. The inclusion of the three stations enables us to provide a broader view of flood risk susceptibility of the whole Kelantan state of Malaysia, which is considered as the most vulnerable state to natural hazards.

\section{Methodology}

\subsection{Determination of flood characteristics}

The hourly river discharge data were analyzed to determine the annual flood and its corresponding volume and duration. The start and the end of a flood event were marked using Hewlett and Hibbert method [27-30]. As shown in Fig. 2, flood event begins from a point when the hydrograph starts to rise to a point on the recession limb where the separation line with a constant slope of 0.0055 liters per second per hectare per hour intersects [28], [29]. The time lapse between the start time (ts) and end time (te) represents the flood duration (D). The flood or stormflow volume (V) is given by the shaded area and peak flow is the maximum flow during the flood event. The annual flood series was determined based on water year (July to June) similar to that done by Yusop [31] for sites in Peninsular Malaysia.

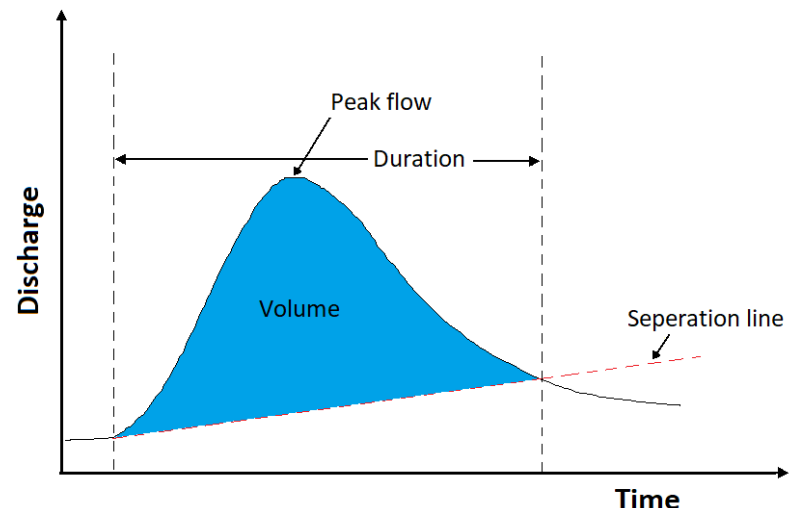

Fig. 2: Illustration of Method Used for Estimation of Flood Variables from a Typical Flood Hydrograph.

\subsection{Univariate distribution of flood variables}

In terms of copula functions, the joint distribution function is a function of the marginal univariate distribution functions. Thus, the univariate Cumulative Distribution Function (CDF) of flood variables need to be fitted from the observed flood data first. The best distribution of flood variables namely, flood duration, flood volume and peak flow were examined by fitting the data using Generalized Pareto, Normal, Log-normal, Exponential, Gamma, Weibull, Gumbel, Cauchy distributions. The KolmogorovSmirnov (K-S) test for goodness of fit [32] was performed at $5 \%$ level of significance. A copula captures the dependence of two or more random variables. The Sklar's theorem [33] states that the joint behavior of random variables $(\mathrm{X}, \mathrm{Y})$ with continuous marginal distributions $\mathrm{u}=\mathrm{F}_{\mathrm{x}}(\mathrm{x})=\mathrm{P}(\mathrm{X} \leq \mathrm{x})$ and $\mathrm{v}=\mathrm{F}_{\mathrm{y}}(\mathrm{y})=\mathrm{P}(\mathrm{Y} \leq \mathrm{y})$ can be characterized uniquely by its associated dependence function or copula, C. For 2-dimensional cases, all (u, v) relationships can be formulated as in Eq. (1).

$\mathrm{F}_{\mathrm{x}, \mathrm{y}}(\mathrm{X}, \mathrm{Y})=\mathrm{C}\left[\mathrm{F}_{\mathrm{x}}(\mathrm{x}), \mathrm{F}_{\mathrm{y}}(\mathrm{y})\right]=\mathrm{C}(\mu, \mathrm{v})$

Where, $F_{(x, y)}(X, Y)$ is the joint $\mathrm{CDF}$ of random variables, $\mathrm{X}, \mathrm{Y}$ and $\forall x, y \in R$. When $I=[0,1]$. The bivariate copula has a distribution function of $\mathrm{C}=\mathrm{I} 2 \rightarrow \mathrm{I}$ which normally satisfies the boundary (Eq. 2) and the increasing property condition (Eq. 3).

$$
\begin{aligned}
& \mathrm{C}(\mathrm{t}, 0)=\mathrm{C}(0, \mathrm{t})=0 \text { and } \mathrm{C}(\mathrm{t}, 1)=\mathrm{C}(1, \mathrm{t})=\mathrm{t}, \forall \mathrm{t}=\mathrm{I} \\
& \mathrm{C}\left(\mathrm{u}_{2}, \mathrm{v}_{2}\right)-\mathrm{C}\left(\mathrm{u}_{2}, \mathrm{v}_{1}\right)-\mathrm{C}\left(\mathrm{u}_{1}, \mathrm{v}_{2}\right)+\mathrm{C}\left(\mathrm{u}_{1}, \mathrm{v}_{1}\right) \geq \\
& 0 \forall \mathrm{u}_{1}, \mathrm{u}_{2}, \mathrm{v}_{1}, € \mathrm{I}
\end{aligned}
$$

such that $\mathrm{u}_{1} \leq \mathrm{u}_{2}$ and $\mathrm{v}_{1} \leq \mathrm{v}_{2}$

The bivariate copula density $\mathrm{C}(\mathrm{u}, \mathrm{v})$ is the double derivative of $\mathrm{C}$ with respect to its marginal and can be expressed as in Eq. (4).

$C(u, v)=\frac{\partial^{2} C(u, v)}{\partial u \partial v}$

Detailed properties and various types of copulas can be found in Krupskii and Joe [34], Parent, et al. [35]; and Shiau and Modarres [36].

\subsection{Copula-based joint distribution of flood variables}

Copulas are used to link the fitted models and construct the joint $\mathrm{CDF}$ of peak flow-duration frequency (QDF), peak flow-volume frequency (QVF) and volume-duration frequency (VDF) [37]. In this study, the Clayton, Frank, Gumbel, t and Gaussian copula were initially employed to model the dependence between a pair of flood variables. The Akaike Information Criterion (AIC) [38] 
that was used to evaluate the fitness of the multivariate copula. The Gumbel was found to fit best for all the joint distribution cases, and therefore, selected for analysis of joint frequency distribution of flood variables. The Gumbel copula has the generator $\varphi(\mu)=(-\ln (\mu))^{\alpha}$, with $\alpha \in[1, \infty]$. for all $\alpha>1$, the copula calculated as:

$\mathrm{C}\left(\mu_{1}, \ldots \mu_{\mathrm{n}}\right)=\exp \left\{-\left[\sum_{\mathrm{i}=1}^{\mathrm{n}}\left(-\ln \mu_{\mathrm{i}}\right)^{\alpha}\right]^{1 / \alpha}\right\}$

The Kendall's tau can be computed as $\tau=1-\alpha^{-1}$. It can be shown that Gumbel copulas have upper tail dependences $\lambda_{\mathrm{U}}=$ $2-2^{1 / \alpha}$ and lower tail dependence vanishing as $\alpha$ diverges to infinity [37].

\section{Results and discussion}

\subsection{General properties of flood variables}

The flood variables namely, annual peak flow, corresponding duration and volume from historical river discharge data for each station were determined. In addition to the mean, maximum, minimum standard deviation and skewness were also determined for each station. It was noticed that the station (5718401) has the highest mean flood duration and peak flow while the station (5120401) has the highest mean of flood volume among the stations used in this study. The averages of flood duration, flood volume, and peak flow at the study area varies between 23 and 171 hours, 0.1 and $1.38 \mathrm{~km}^{3}$, and 81 and $7140 \mathrm{~m}^{3} / \mathrm{sec}$, respectively.

\subsection{Determination of best-fitted distributions of flood variables}

Various univariate distribution functions including Pareto, lognormal, exponential, gamma distribution, Weibull, Gumbel, Cauchy were used to determine the best fit for flood variables. The goodness of fit for different distributions was carried out based on Kolmogorov-Smirnov (KS). The obtained results are provided in Table 1. It was observed that there is no consistency of distributions for duration, volume and peak flow. For example, at station (5120401), a gamma distribution was found best fit for peak flow, a normal distribution for flood duration, and exponential for flood volume. Similar types of results were also observed at other stations. Overall, normal or log-normal was found to fit flood duration in most of the stations, exponential or log-normal for flood volume, and gamma or Gumbel for peak flood flow.

\subsection{Univariate return periods of flood variables}

The best-fitted distributions of flood variables were used for estimation of return periods of flood variables at different locations. Obtained results are presented in Fig. 3.

Table 1: The Best Fitted Distribution Function of Flood Variables at Different Stations

\begin{tabular}{lllllll}
\hline \multirow{2}{*}{ Variable } & \multicolumn{7}{c}{ Station ID } \\
\cline { 2 - 7 } Flow & 5120401 & 5222452 & 5320438 & 5320443 & 5419401 & 5621401 \\
Duration & $\mathrm{G}$ & $\mathrm{G}$ & $\mathrm{G}$ & $\mathrm{G}$ & $\mathrm{G}$ & $\mathrm{G}$ \\
Volume & $\mathrm{E}$ & $\mathrm{E}$ & $\mathrm{N}$ & $\mathrm{N}$ & $\mathrm{LN}$ & $\mathrm{LN}$ \\
\hline \multirow{2}{*}{ Variable } & & $\mathrm{N}$ & $\mathrm{E}$ & $\mathrm{LN}$ & $\mathrm{LN}$ & $\mathrm{E}$ \\
\cline { 2 - 7 } & 5718401 & 5721442 & 5818401 & 6022421 & 6019411 & 6021401 \\
Flow & $\mathrm{Gm}$ & $\mathrm{G}$ & $\mathrm{Gm}$ & $\mathrm{Gm}$ & $\mathrm{Gm}$ & $\mathrm{Gm}$ \\
Duration & $\mathrm{C}$ & $\mathrm{N}$ & $\mathrm{LN}$ & $\mathrm{Gm}$ & $\mathrm{LN}$ & $\mathrm{Gm}$ \\
Volume & $\mathrm{LN}$ & $\mathrm{E}$ & $\mathrm{W}$ & $\mathrm{Gm}$ & $\mathrm{LN}$ & $\mathrm{W}$ \\
\hline
\end{tabular}

Notation: G: Gamma; N: Normal; E: Exponential; LN: Log-Normal; Gm:

Gumbel; W: Weibull; and C: Cauchy.
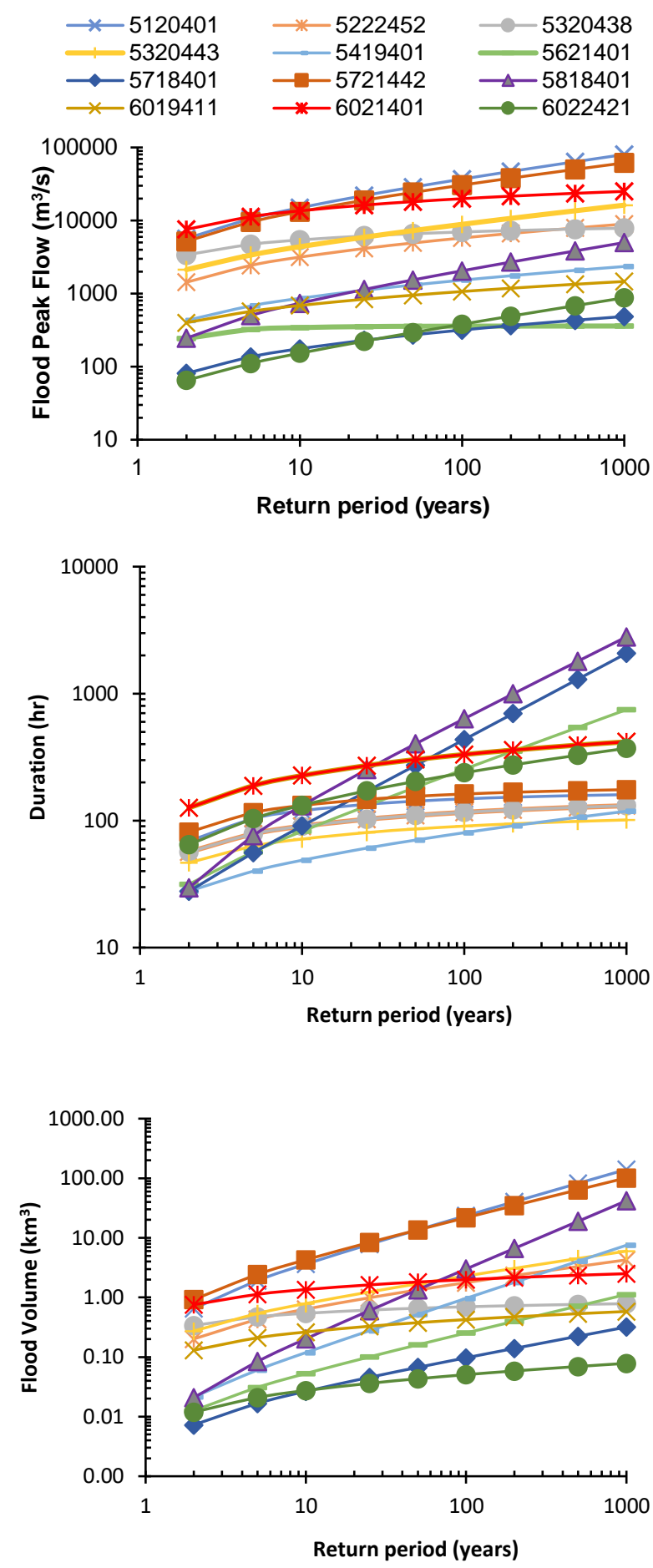

Fig. 3: The Return Period of (Upper) Peak Flood Flow $\left(\mathrm{m}^{3} / \mathrm{s}\right)$; (Middle) Duration (hr); and (Lower) Volume $\left(\mathrm{Km}^{3}\right)$ at Different Locations in Kelan$\tan$

\subsection{Correlations between flood variables}

The correlation among different flood variables at all the stations was assessed. The distribution of flood variables, scatter plots and correlations between two pairs of flood variables at station (5222452) is shown as an example in Fig. 4. The linear correlations among flood variables at all the stations are presented in Fig. 5. 


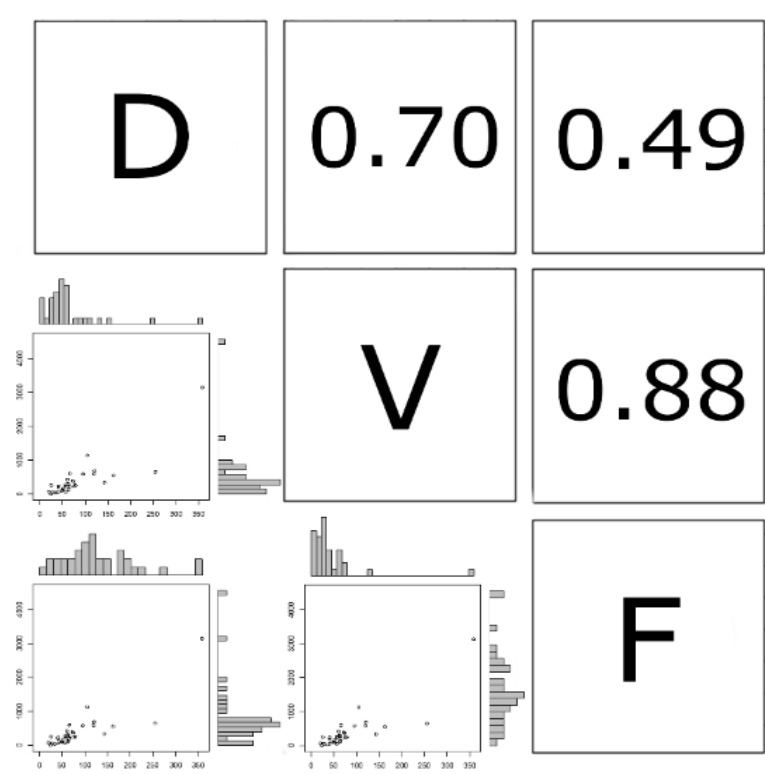

Fig. 4: The Correlation between Two Flood Variables in A Matrix Format at Station (5222452). The Variables are Peak Flow (F), Duration (D), and Volume (V).

The figure shows high dependency among flood variables, particular dependency between flood volume and duration was found very high at all stations. Association between peak flow and flood volume was also found very high at many stations. However, the relationship is relatively weak between duration and flow. The relationship varies over different stations. Highest correlation of 0.96 between duration and volume was observed over station (5120401). It can be seen that most of the stations have a correlation above 0.5 . In addition to this, flow and volume also have a good relationship where most of the stations have a correlation of above 0.5 . Stations (6019411) have the highest correlation of 0.99 . It is important to mention here that station (5120401) which showed the highest correlation of 0.96 between duration and volume showed lower relationship in flow and volume (0.2). A negative correlation was also observed over station
(5818401) for duration and flow and over station (5320438) for flow and volume.

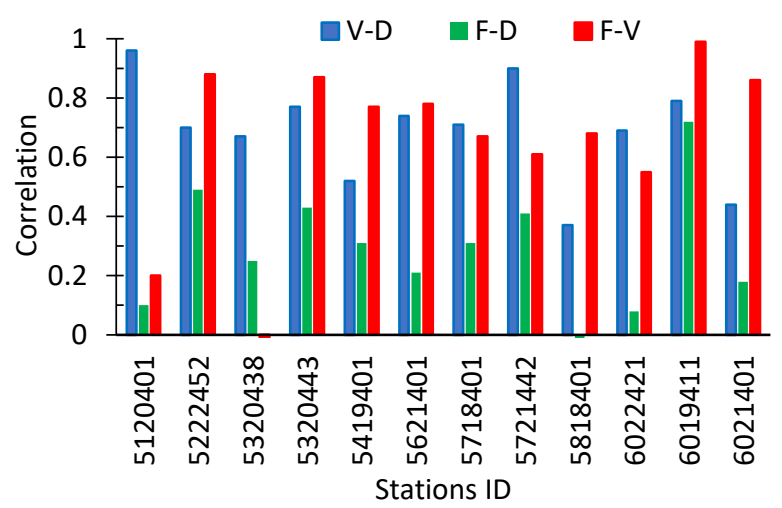

Fig. 5: Correlation between Flood Variables at Different Locations of Kelantan River Basin (F: Peak Flow; V: Volume; and D: Duration).

\subsection{Copula analysis of flood variables}

The pairs of flood variables were modeled using Gumbel copula. Obtained results are presented in Fig. 6. The figure demonstrates the bivariate return period of flood events over station (5120401) and station (5721442). The contour lines in the figure represent the return period of flood event while $\mathrm{x}$ and $\mathrm{y}$-axis are different combinations of flood peak, volume, and duration. Red dots represent the observed data while grey dots represent the simulations. It can be seen that flood is more frequent at low return periods and duration of peak flood is low. The figures provide quick information on volume, duration, and peak. For example, a flood volume of $2 \mathrm{~km}^{3}$ can generate a peak flow of around $8000 \mathrm{~cm}^{3} / \mathrm{s}$ at 2 years return period. Similarly, a flood volume of $2 \mathrm{~km}^{3}$ can happen for 60 hours. On the other hand, a flood peak of $10,000 \mathrm{~cm}^{3} / \mathrm{s}$ can occur approximately in 75 hours. Similar types of information can be extracted from the figures of other stations.
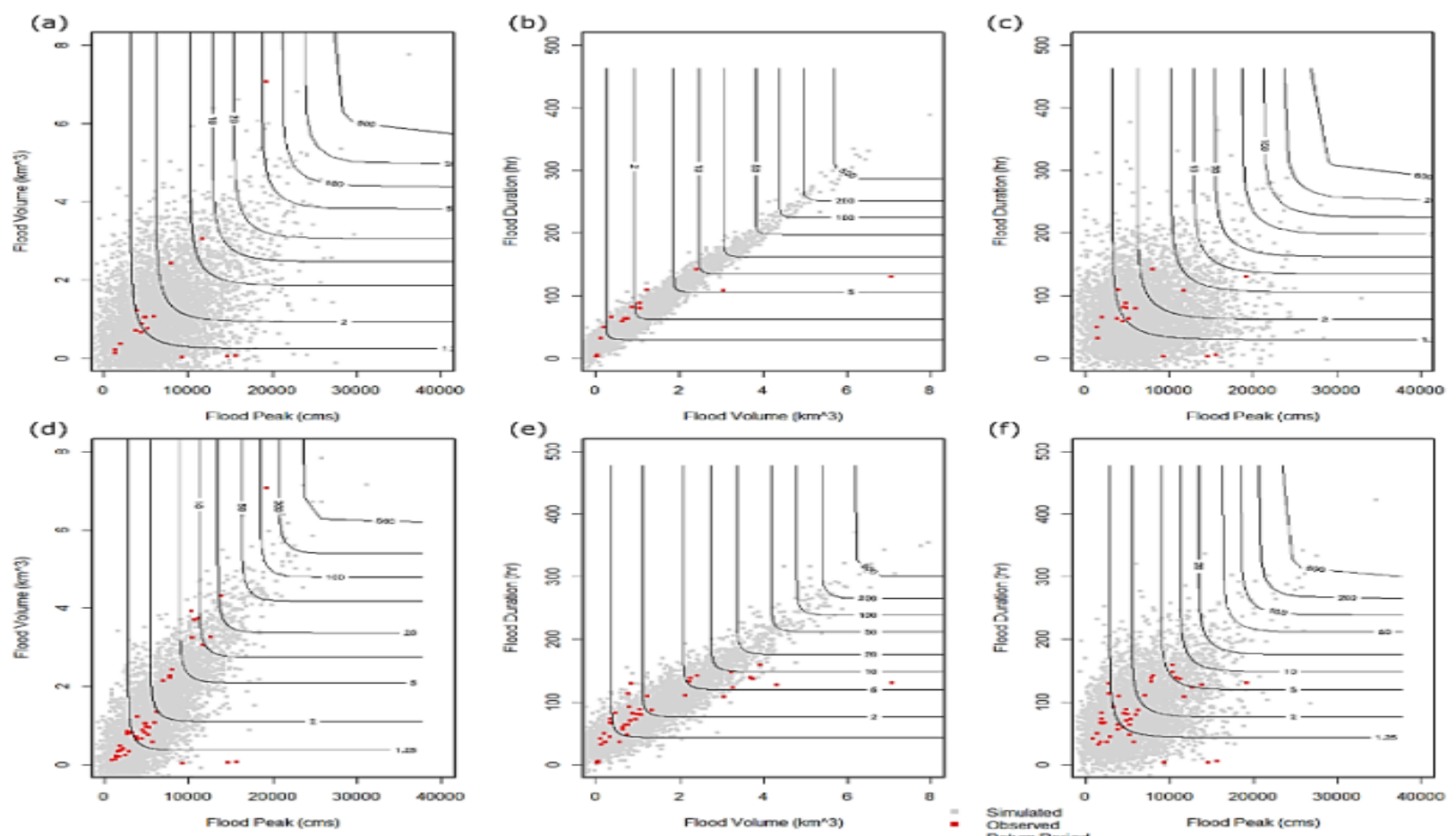

Fig. 6: Gumbel Copula of (A) Flood Peak and Volume; (B) Flood Volume and Duration; and (C) Flood Peak and Duration for Station (5120401) at The Upper Row and (D) Flood Peak and Volume; (E) Flood Volume and Duration; and (F) Flood Peak and Duration for Station (5721442) at the Lower Row. 


\subsection{Bivariate return period of flood variables}

The pairs of flood variables were modeled using Gumbel copula to estimate the joint return periods of flood variables. The joint return periods of flood variables at two catchments where flood peaks were found highest among all the catchments are shown in Fig. 7. The 10-year return amount of flood peak flow for flood volume of $6 \mathrm{~km}^{3}$ was found 10,125 and $13,094 \mathrm{~m}^{3} / \mathrm{s}$ at stations (5721442) and (5120401), respectively. This value is much high compared to a 10-year return period of peak flood flow estimated using the univariate distribution of peak flow. A similar discrepancy was observed for a joint return and univariate return values of other flood variables. This indicates the importance of analysis of joint return period of flood variables for flood risk assessment.
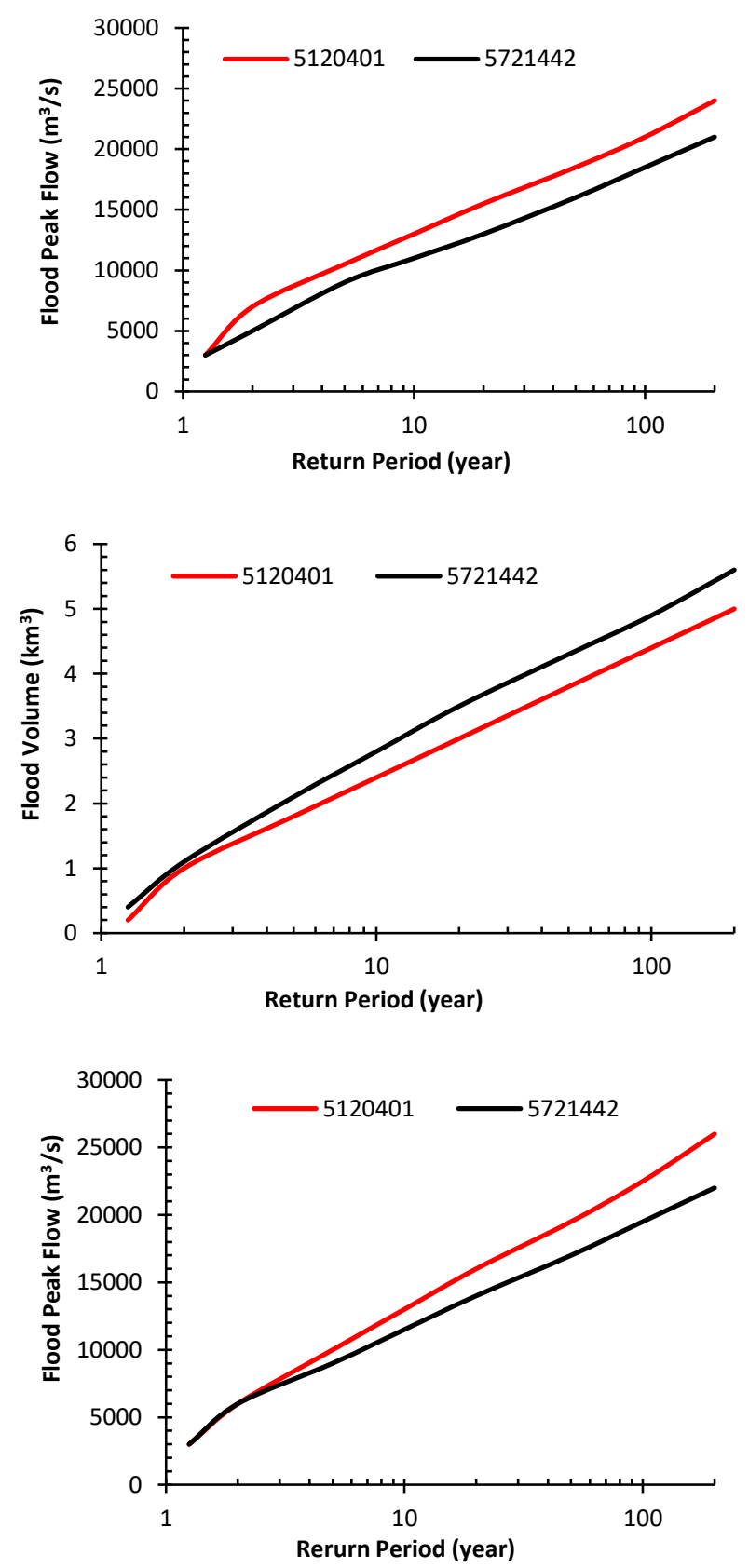

Fig. 7: Joint Return Period of Flood Variables at Two High Flood Susceptible Locations of Kelantan River Basin: Peak Flood for Six $\mathrm{Km}^{3}$ Flood Volume (Upper); Flood Volume for Flood Duration of 300 Hours (Middle); Peak Flood Flow for Duration of 300 Hours (Lower).

\subsection{Local-scale flood risk based on joint return periods}

Flood risk in different locations of Kelantan River basin was assessed based on flood volume generated per $\mathrm{km}^{2}$ of the area that contributing runoff to that point. The estimated volume was then used in copula function to estimate the joint return amount of peak flow and duration for that the flood for each station. The flood peak flow, volume, and duration at each location for three different return periods namely, 10-, 50- and 100-year are shown in Fig. 8. The higher values of flood variables at a station location indicate higher risk. The figure clearly shows the higher volume of flood water, high peak flow and long duration of flood for all the return period at station (5621401), which indicates a higher risk of flood devastation in this region of Kelantan basin compared to others. The triangular shape of the basin has made this location highly susceptible to flood. The areas in the vicinity of the stations were severely affected by floods in 2014 . The results indicate the importance of the joint distribution of flood variables for assessing flood risk at gauged locations and thus, the spatial distribution of floods in river basins.
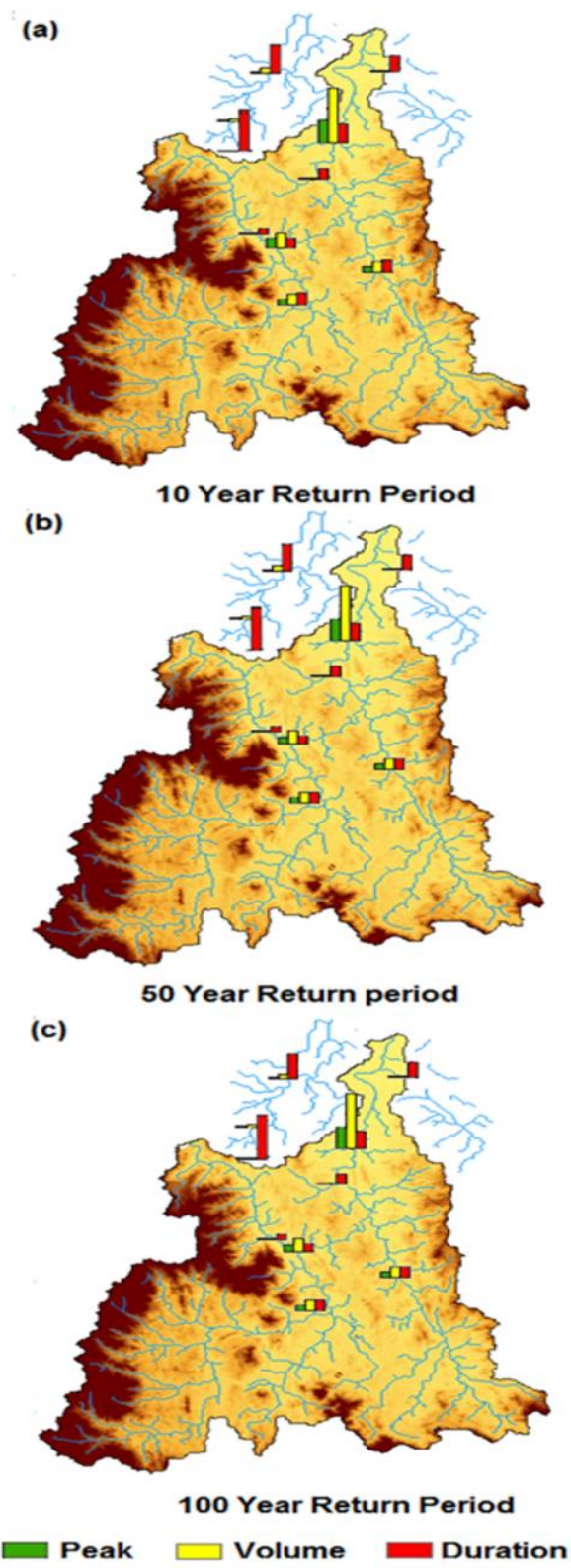

Fig. 8: Flood Risk in Different Locations of Kelantan River Basin with (A) a 10-Year; (B) a 50-Year; and (C) a 100-Year Return Period. 


\section{Conclusion}

Destructive floods occur when high flood peak sustain for a longer period or huge volume of flood water inundates an area for a longer time. This emphasizes the need to study the joint distribution of flood variables together. In this study, three flood variables namely; peak flow, duration, and volume were separately modeled by a probabilistic distribution function. The fitted models were linked using the concept of copula to construct joint bivariate distribution function of peak flow-duration, peak flow-volume, and volumeduration. Based on KS, the different distribution fits were found for different flood variables. The correlation among flood variables including duration, volume and flow indicates that there is a good agreement between duration and volume, volume and flow. The results indicate that bivariate copula provides more information on floods, which cannot be obtained by univariate flood frequency analysis. The novelty of the study is that the bivariate distribution of flood variables is used for the assessment of flood risk based on all the three flood properties together. The application of the method at different gauging locations of Kelantan River basin was found to identify the higher flood risk areas efficiently. The spatial map of flood risk could not be generated due to the limited availability of river discharge data at a limited number of stations. Furthermore, the stations are not aligned according to sub-catchment outlets in the river basin and therefore, it was not possible to rank the sub-catchments according to flood risk. Such studies can be conducted in another river basin where data is available to show the efficacy of the method proposed in this study for flood risk analysis.

\section{Acknowledgment}

The authors would like to acknowledge Universiti Teknologi Malaysia (UTM) for providing financial support for this research through RUG Grant No Q.J130000.2522.13H07.

\section{References}

[1] K. Ahmed, E.-S. Chung, J.-Y. Song, and S. Shahid, "Effective Design and Planning Specification of Low Impact Development Practices Using Water Management Analysis Module (WMAM): Case of Malaysia," Water, vol. 9, no. 3, p. 173, 2017. https://doi.org/10.3390/w9030173.

[2] A. Katimon, S. Shahid, and M. Mohsenipour, "Modeling water quality and hydrological variables using ARIMA: a case study of Johor River, Malaysia," Sustainable Water Resources Management, pp. 1-8, 2017.

[3] M. Salarpour, Z. Yusop, F. Yusof, S. Shahid, and M. Jajarmizadeh, "Flood Frequency Analysis Based on Gaussian Copula," Singapore, 2016, pp. 151-165: Springer Singapore. https://doi.org/10.1007/978-981-10-0500-8 13.

[4] M. Salarpour, Z. Yusop, F. Yusof, S. Shahid, and M. Jajarmizad, "Flood frequency analysis based on t-copula for Johor River, Malaysia," Journal of Applied Sciences, vol. 13, pp. 1021-1028, 2013. https://doi.org/10.3923/jas.2013.1021.1028

[5] L.-S. Chen, I. S. Tzeng, and C.-T. Lin, "Bivariate generalized gamma distributions of Kibble's type," Statistics, vol. 48, no. 4, pp. 933-949, 2014/07/04 2013

[6] A. I. Requena, L. Mediero, and L. Garrote, "A bivariate return period based on copulas for hydrologic dam design: accounting for reservoir routing in risk estimation," Hydrology and Earth System Sciences, vol. 17, no. 8, pp. 3023-3038, 2013 https://doi.org/10.5194/hess-17-3023-2013.

[7] G. Salvadori and C. De Michele, "Multivariate Extreme Value Methods," in Extremes in a Changing Climate, A. AghaKouchak, D. Easterling, K. Hsu, S. Schubert, and S. Sorooshian, Eds. (Water Science and Technology Library, Dordrecht: Springer Netherlands, 2013, pp. 115-162. https://doi.org/10.1007/978-94-007-4479-0 5.

[8] H. Chowdhary, L. A. Escobar, and V. P. Singh, "Identification of suitable copulas for bivariate frequency analysis of flood peak and flood volume data," Hydrology Research, vol. 42, no. 2-3, pp. 193 216, 2011. https://doi.org/10.2166/nh.2011.065.
[9] S.-C. Kao and N.-B. Chang, "Copula-Based Flood Frequency Analysis at Ungauged Basin Confluences: Nashville, Tennessee," Journal of Hydrologic Engineering, vol. 17, no. 7, pp. 790-799, 2012. https://doi.org/10.1061/(ASCE)HE.1943-5584.0000477.

[10] L. Chen, V. P. Singh, G. Shenglian, Z. Hao, and T. Li, "Flood Coincidence Risk Analysis Using Multivariate Copula Functions," Journal of Hydrologic Engineering, vol. 17, no. 6, pp. 742-755, 2012. https://doi.org/10.1061/(ASCE)HE.1943-5584.0000504.

[11] T. Li, S. Guo, L. Chen, and J. Guo, "Bivariate Flood Frequency Analysis with Historical Information Based on Copula," Journal of Hydrologic Engineering, vol. 18, no. 8, pp. 1018-1030, 2013. https://doi.org/10.1061/(ASCE)HE.1943-5584.0000684.

[12] M. J. Reddy and P. Ganguli, "Bivariate Flood Frequency Analysis of Upper Godavari River Flows Using Archimedean Copulas," Water Resources Management, journal article vol. 26, no. 14, pp. 3995-4018, November 012012.

[13] H. Xie and K. Wang, "Joint-probability Methods for Precipitation and Flood Frequencies Analysis," in 2013 Third International Conference on Intelligent System Design and Engineering Applications, 2013, pp. 913-916. https://doi.org/10.1109/ISDEA.2012.217.

[14] S. Shahid, P. S. Hadi, W. Xiaojun, S. S. Ahmed, M. Anil, and I. T. bin, "Impacts and adaptation to climate change in Malaysian real estate," (in English), International Journal of Climate Change Strategies and Management, vol. 9, no. 1, pp. 87-103, 2017. https://doi.org/10.1108/IJCCSM-01-2016-0001.

[15] H. Obaid and S. Shahid, "Soil erosion susceptibility of Johor River basin," Water and Environment Journal, vol. 31, no. 3, pp. 367-374, 2017. https://doi.org/10.1111/wej.12252.

[16] S. H. Pour, S. B. Harun, and S. Shahid, "Genetic programming for the downscaling of extreme rainfall events on the East Coast of Peninsular Malaysia," (in English), Atmosphere, vol. 5, no. 4, pp. 914-936, Dec 2014. https://doi.org/10.3390/atmos5040914.

[17] O. O. Mayowa et al., "Trends in rainfall and rainfall-related extremes in the east coast of peninsular Malaysia," Journal of Earth System Science, vol. 124, no. 8, pp. 1609-1622, 2015. https://doi.org/10.1007/s12040-015-0639-9.

[18] R. Ibbitt, K. Takara, M. N. B. M. Desa, and H. Pawitan, "Catalogue Of Rivers For South East Asia And The Pacific-Volume IV," ed: The UNESCO-IHP Regional Steering Committee for Southeast Asia and the Pacific, UNESCO-IHP Publication, 2002.

[19] Z. Sa'adi, S. Shahid, T. Ismail, E.-S. Chung, and X.-J. Wang, "Trends analysis of rainfall and rainfall extremes in Sarawak, Malaysia using modified Mann-Kendall test," Meteorology and Atmospheric Physics, journal article November 142017.

[20] N. N. A. Tukimat, S. Harun, and S. Shahid, "Comparison of different methods in estimating potential evapotranspiration at Muda Irrigation Scheme of Malaysia," Journal of Agriculture and Rural Development in the Tropics and Subtropics (JARTS), vol. 113, no. 1 , pp. 77-85, 2012.

[21] J. A. Shakirah et al., "A Review on Flood Events for Kelantan River Watershed in Malaysia for Last Decade (2001-2010)," IOP Conference Series: Earth and Environmental Science, vol. 32, no. 1, p. 012070, 2016. https://doi.org/10.1088/1755-1315/32/1/012070.

[22] B. Pradhan and A. Youssef, "A 100-year maximum flood susceptibility mapping using integrated hydrological and hydrodynamic models: Kelantan River Corridor, Malaysia," Journal of Flood Risk Management, vol. 4, no. 3, pp. 189-202, 2011. https://doi.org/10.1111/i.1753-318X.2011.01103.x.

[23] M. M. A. Khan, N. A. B. Shaari, A. M. A. Bahar, M. A. Baten, and D. A. B. Nazaruddin, "Flood impact assessment in Kota Bharu, Malaysia: a statistical analysis," World Applied Sciences Journal, vol. 32, no. 4, pp. 626-634, 2014

[24] A. Omran, O. Schwarz-Herion, and A. A. Bakar, "Factors Contributing to the Catastrophic Flood in Malaysia," in The Impact of Climate Change on Our Life: The Questions of Sustainability, A. Omran and O. Schwarz-Herion, Eds. Singapore: Springer Singapore, 2018, pp. 33-55. https://doi.org/10.1007/978-981-10-7748-7__2.

[25] W. I. W. Ahmad and S. M. Abdurahman, "Kelantan Flood 2014: Reflections from Relief Aid Mission to Kampung Kemubu, Kelantan," Mediterranean Journal of Social Sciences, vol. 6, no. 3 S2, p. 340, 2015.

[26] T. Star. (2017, 3-3-2018). Over 14,000 evacuated as floods worsen in Kelantan. Available: https://www.thestar.com.my/news/nation/2017/12/01/over-14000evacuated-as-floods-worsen-in-kelantan/

[27] J. D. Hewlett and A. R. Hibbert, "Factors affecting the response of small watersheds to precipitation in humid areas," Forest hydrology, vol. 1, pp. 275-290, 1967

[28] M. A. B. Aissia et al., "Multivariate analysis of flood characteristics in a climate change context of the watershed of the Baskatong res- 
ervoir, Province of Québec, Canada," Hydrological Processes, vol. 26, no. 1, pp. 130-142, 2012. https://doi.org/10.1002/hyp.8117.

[29] C. O'Driscoll, "Assessment and mitigation of forest clearfelling impacts on salmonid receiving waters," 2012.

[30] Z. Yusop, I. Douglas, and A. R. Nik, "Export of dissolved and undissolved nutrients from forested catchments in Peninsular Malaysia," Forest ecology and management, vol. 224, no. 1-2, pp. 26-44, 2006. https://doi.org/10.1016/j.foreco.2005.12.006.

[31] Z. Yusop, "Effects of Logging on Streamwater Quality and Solute Input-output Budgets in Small Watersheds in Peninsular Malaysia," Universiti Pertanian Malaysia, 1990.

[32] F. J. Massey Jr, "The Kolmogorov-Smirnov test for goodness of fit," Journal of the American statistical Association, vol. 46, no. 253, pp. 68-78, 1951. https://doi.org/10.1080/01621459.1951.10500769.

[33] M. Sklar, "Fonctions de repartition an dimensions et leurs marges," Publ. Inst. Statist. Univ. Paris, vol. 8, pp. 229-231, 1959.

[34] P. Krupskii and H. Joe, "Factor copula models for multivariate data," Journal of Multivariate Analysis, vol. 120, pp. 85-101, 2013. https://doi.org/10.1016/j.jmva.2013.05.001.

[35] E. Parent, A.-C. Favre, J. Bernier, and L. Perreault, "Copula models for frequency analysis what can be learned from a Bayesian perspective?," Advances in water resources, vol. 63, pp. 91-103, 2014. https://doi.org/10.1016/j.advwatres.2013.10.013.

[36] J.-T. Shiau and R. Modarres, "Copula-based drought severityduration-frequency analysis in Iran," Meteorological Applications, vol. 16, no. 4, pp. 481-489, 2009. https://doi.org/10.1002/met.145.

[37] R. B. Nelsen, An introduction to copulas. Springer Science \& Business Media, 2007.

[38] H. Akaike, "A new look at the statistical model identification," IEEE Transactions on Automatic Control, vol. 19, no. 6, pp. 716723, 1974. https://doi.org/10.1109/TAC.1974.1100705. 